Khan, M.A., Jiang, L., Cashell, K.A., Usmani, A.S. Virtual hybrid simulation of beams with web openings in fire. Accepted for publication in Structural Fire Engineering, 2019

\title{
VIRTUAL HYBRID SIMULATION OF BEAMS WITH WEB OPENINGS IN FIRE
}

Mustesin Ali Khan ${ }^{a}$, Liming Jiang, ${ }^{b,}$, Katherine A. Cashell ${ }^{\mathrm{a}}$, Asif Usmani ${ }^{\mathrm{b}}$

a Department of Civil Engineering, Brunel University London, UK

${ }^{\boldsymbol{b}}$ Department of Building Services Engineering, The Hong Kong Polytechnic University, Hong Kong

\begin{abstract}
Purpose - Perforated composite beams are an increasingly popular choice in the construction of buildings as they can provide a structurally and materially efficient design solution whilst also facilitating the passage of services. This paper is concerned with the behaviour of restrained perforated beams which act compositely with a profiled slab and are exposed to fire. The effect of surrounding structure on the composite perforated beam is incorporated in this study using a virtual hybrid simulation framework.

Design/methodology/approach - A finite element model is developed using OpenSees and OpenFresco utilising a virtual hybrid simulation technique, and the accuracy of the model is validated using available fire test data. The validated model is used to investigate some of the most salient parameters such as the degree of axial and rotational restraint, arrangement of the openings and different types of fire on the overall fire behaviour of composite perforated beams.
\end{abstract}

Findings - It is shown that both axial and rotational restraint have a considerable effect on time-displacement behaviour and the fire performance of the composite perforated beam. It is observed that the rate of heating and the consequent development of elevated temperature in the section have a significant effect on the fire behaviour of composite perforated beams.

Originality value - The paper will improve the knowledge of readers about modelling the whole system behaviour in structural fire engineering in a computationally efficient manner without modelling the whole structure in 3D.

Keywords - Perforated beams, OpenSees, OpenFresco, virtual hybrid simulation.

Paper type - Research paper 


\section{Introduction}

Perforated steel beams are synonymous with modern long-span construction, and are regularly specified in sports arenas, airport terminals and multi-storey buildings. They are typically manufactured either by cutting openings of the desired shape in the web of a hot-rolled steel section or by fabricating the section from steel plates similar to a plate girder. The most popular shapes for the web openings are circular (to give a cellular beam), rectangular, elongated and sinusoidal openings. The solid region between two adjacent openings is called the web-post, and its dimensions vary depending on the opening arrangement. Perforated beams are often preferred in high-rise buildings to regular I-shaped sections as longer spans can be achieved resulting in large column-free spaces and reduced construction time. In addition, building services such as electrical cables and heating/ventilation pipework can easily pass through the web openings, thus reducing the overall height of the building and requirements for additional materials. It has been noted previously that perforated beams often provide a more economical solution compared with solid beams and result in significantly lower material requirements (Nadjai et al., 2017).

The fire behaviour of structures has been the subject of intensive research in recent decades (British Steel Plc, 1999; Dwaikat and Kodur, 2011; Li and Guo, 2008; Liu et al., 2002; Maraveas et al., 2017, 2018) and is particularly topical for high-rise structures at the current time following the fire at Grenfell Tower in London in 2017 (McKenna et al., 2019). Owing to the many complexities involved in fire conditions, most research focusses on the behaviour of isolated structural components, without necessarily including the whole structure in the analysis, usually idealising the effect of the surrounding structure. In fact, the majority of research studies on perforated beams to date have concentrated on beams with simply supported boundary conditions (Ellobody and Young, 2015; Nadjai et al., 2007, 2016; Wong et al., 2009). This has been a valid and necessary step towards gaining a greater understanding of the behaviour, although it has been noted that the majority of composite perforated beams in practice experience some degree of both axial and rotational restraint (Najafi and Wang, 2017a). Moreover, the behaviour of the beams during a fire is very much dependent on the type and magnitude of the restraint developed by the surrounding structure (Najafi and Wang, 2017b, 2017a).

In this context, the current study is focused on the fire behaviour of perforated steel beams which are acting compositely with a profiled slab, and have various degrees of axial and/or rotational support. One of the largest studies into restrained perforated beams in fire was 
conducted at the Czech Technical University and the University of Ulster (Nadjai et al., 2011; Wald et al., 2011). This project included large-scale fire tests however some important parameters which give an insight into the overall behaviour such as the axial reactions were not measured. Further numerical and analytical analyses were conducted in which different levels of axial restraint were considered and uniform temperature distribution was assumed (Najafi and Wang, 2017a, 2017b), but the influence of rotational restraint, composite action due to the slab and different fire scenarios was not included. A simplified method for analysing frames comprising cellular beams which are subjected to fire has been proposed (Abu et al., 2009). In this method, the web openings are not directly incorporated but their effect is represented using an equivalent web thickness, resulting in a solid beam. However, various failure modes associated specifically with perforated beams such as web-post buckling and Vierendeel bending cannot be realistically predicted using this approach.

In summary, there is a lack of data and analysis on the behaviour of restrained composite perforated beams in fire conditions in the literature. Accordingly, the current paper aims to study this behaviour using a virtual hybrid simulation numerical approach. In this method, the structure is divided into two sub-sections or assemblies, and the area which is expected to undergo large deformations (i.e., the perforated beam which is subjected to fire) is modelled in fine numerical detail using shell elements in one assembly whilst the surrounding structure which should behave elastically is modelled using beam-column elements in another assembly at a much lower computational cost. A middleware or interaction software such as OpenFresco (Kwon et al., 2007; Takahashi and Fenves, 2006) is used to connect the two assemblies at the interface. Modelling the whole structure in 3D is a complex and computationally expensive task. On the other hand, the proposed method is capable of analysing the whole system behaviour in a computationally efficient manner. This approach produces an extremely powerful and versatile tool for efficient and accurate simulations of large structural systems subjected to complex fire scenarios.

In addition, hybrid simulation combining physical testing with numerical analysis has been receiving greater attention in recent years, especially in earthquake engineering applications, and its value and efficiency has been recognised (Pegon and Pinto, 2000). Most of the recent hybrid testing in fire was performed at the National Research Council Canada's (NRC) testing facilities in Ottawa (Mostafaei, 2012, 2013). In these studies, the interaction between the physical and numerical substructures was not automatic but was user-controlled, meaning that the user paused the physical test every five minutes to log the numerical data and then the 
simulation was re-started. The accuracy of this approach was compromised due to the manual nature of the test. The number of responses communicated between the two assemblies was also limited. Only the axial displacements and axial reaction forces were communicated between the test and the model, by assuming that the column was axially loaded and the geometry was symmetrical.

However, due to the challenges involved in conducting hybrid testing and simulation in fire conditions, it is sensible to develop and verify a framework in a fully numerical environment. The successful implementation of a virtual hybrid simulation framework eliminates the requirement for manual involvement between the two assemblies and this framework can then be employed in the future by replacing the detailed FE model with a physical substructure. In this approach, many different responses can be controlled and communicated at the interface between the two substructures.

\section{Development of the virtual hybrid simulation framework}

The term hybrid simulation typically refers to a two-part structural analysis where the portion of the structure which is subjected to extreme loading and expected to undergo large deformations is physically tested in the laboratory whilst the rest of the surrounding structure is simulated using a finite element analysis model. The physical test and numerical model are in constant communication throughout the analysis, with deformations, temperature distributions, member reactions and restraint conditions constantly updating and being transferred between the two assemblies. In the current work, the physical testing component of hybrid simulation is replaced by a detailed numerical model to create a so-called virtual hybrid simulation, in order to establish a viable and efficient framework. The restrained perforated beam which is exposed to fire is modelled in fine detail using 3D shell elements whilst the surrounding structure is modelled using simpler beam-column elements. Once validated, this framework can later be utilised to perform hybrid testing of structural components in fire conditions, which is a complex and expensive process.

\subsection{OpenSees}

OpenSees is an open-source finite element analysis software which was originally developed for earthquake engineering applications at the University of California, Berkeley (McKenna, 1997). Owing to its open-source framework, OpenSees is a collaborative programme which allows developers to add components to the original source code depending on their particular needs, and then disseminate these developments to other potential users. It is constantly being 
developed by researchers for different types of application (Jiang and Usmani, 2018; Kolozvari et al., 2018; Zhu et al., 2018), including structural fire engineering (Usmani et al., 2010). OpenSees is an object-oriented software implemented in the $\mathrm{C}++$ programming language, using the 'Tcl' scripting language. In this study, OpenSees is utilised to model all the assemblies of virtual hybrid simulation. The compatibility of OpenSees with the middleware OpenFresco enables the user to couple the two assemblies or to establish a communication between the physical test and the numerical model as both software are implemented in $\mathrm{C}++$ programming language.

\subsection{OpenFresco}

There are a number of different approaches for enabling the two assemblies to communicate with each other such as OpenFresco (Takahashi and Fenves, 2006), Ui-Simcor (Kwon et al., 2007) or a file exchange system. In the current study, the data is transferred between the two codes using the OpenFresco middleware software. OpenFresco is preferred over other communication methods because this software is also implemented in $\mathrm{C}++$ programming language similar to OpenSees. Using this method for data communication between the two programmes enables both FE codes to run simultaneously, without restarting the analysis at every time step. This reduces the complexity and enhances the computational efficiency of the process, compared with the file exchange system. Accordingly, OpenFresco facilitates the storage, transformation and transfer of data between two assemblies.

\subsection{Development of the model}

The analysis is performed using a virtual hybrid simulation approach. In virtual hybrid simulation, the structure is divided into two substructures. The part of the structure which is exposed to fire and expected to experience large deformations is modelled using complex 3D elements (shell and brick elements) in a substructure named the slave assembly whilst the remainder of the structure is modelled using simpler elements (beam-column elements) in another substructure named the master assembly.

The numerical model is developed based on the fire test at an administrative building in Mokrsko, Poland, which included a composite cellular beam subjected to fire (Wald et al., 2011). The beam was made using an IPE 270 profile with an overall length and depth of $9 \mathrm{~m}$ and $395 \mathrm{~mm}$, respectively, using grade S235 steel, and was named AS2 in the study. There were 8 sinusoidal openings at equal spacings along the span. The profiled slab had an overall depth of $120 \mathrm{~mm}$, including a flat portion and ribs which were $60 \mathrm{~mm}$ each in depth, and was made using concrete with a compressive strength of $32.5 \mathrm{MPa}$. The slab was lightly reinforced 
with $5 \mathrm{~mm}$ diameter bars, at $100 \mathrm{~mm}$ spacing in both directions, located at the mid-depth of the flat portion of the cross-section. IPE 400 sections were used for the edge beams, also in grade S235 steel, whilst the columns were made using HEB 180 sections.

In the virtual hybrid simulation model, the part of the structure exposed to the fire (i.e. the AS2 composite beam) is represented using high resolution $3 \mathrm{D}$ elements in a slave assembly whilst less detailed elements are employed for the rest of the structure in a master assembly. OpenSees is utilised to model both the slave and master assemblies. The cellular steel beam is modelled using 3D shell elements (ShellMITC4Thermal) available in OpenSees. The composite slab is modelled using 3D beam-column elements for the ribs (3DbeamcolumnThermal), and 3D shell elements (ShellMITC4Thermal) for the flat portion. The reinforcement is modelled using a smeared layer approach. The cellular beam is connected to the slab using link elements called rigidlink in OpenSees. The thermal and mechanical properties for both concrete and steel at elevated temperature are defined in accordance with the Eurocode (EN 1992-1-2, 2004; EN 1993-1-2, 2005) and implemented to the model through the material classes available in OpenSees. The J2plasticityThermal material class (Khan et al., 2018) is employed for representing the structural steel response at elevated tempearture and the SteelECThermal class is used for the steel reinforcement. For the concrete slab, the Concrete02Thermal and ConcreteDamagedPlasticity material classes which are available in OpenSees are utilised to model the material in the ribs and slab, respectively, at elevated temperature. In the fire test, the openings were sinusoidal in shape. However, in order to simplify the model, the openings are idealised herein as rectangles with equivalent opening areas to the test specimens, in accordance with the guidelines given in SCI P355 design manual (Lawson and Hicks, 1998). In the model, each rectangular opening has dimensions of $625 \times 250 \mathrm{~mm}$. The remainder of the frame comprising the adjacent primary beam (IPE 400) and columns (HEB 180) is modelled using 3D beam-column elements in the master assembly in OpenSees.

The communication between the two assemblies is facilitated using OpenFresco. A superelement at the interface nodes in the master assembly and an adapter element at the interface nodes in the slave assembly are defined to connect the two FE assemblies. The communication between the two substructures takes place according to the following sequence of steps (See Fig. 1).

Step 1. The master assembly generates a displacement vector of global trial displacements $\left(\mathrm{u}_{\text {super }}\right.$ ) for all of its degrees of freedom at the interface nodes. 
Step 2. The displacement vector obtained in the previous step is sent to OpenFresco using a TCP/IP socket (Transmission Control Protocol/Internet Protocol) as can be seen in Fig. 1. Here the 'SimAppSiteServer' class of OpenFresco start the simulation server process.

Step 3. The displacement vector is stored and transformed by the 'LocalExpSite' and 'ExperimentalSetup' objects (see Fig. 1). The transformation of the data is not required in this instance because no physical specimen (i.e. laboratory test specimen) is involved. So, the 'NoTransformation' object as 'ExpSetup' is utilised.

Step 4. The trial displacement vector is then sent to the 'ExperimentalControl' object which feeds the trial displacement vector to the adapter element in the slave assembly. The adapter element then forms a resultant displacement vector by combining the trial displacements $\left(\mathrm{u}_{\text {super }}\right)$ with its own elemental displacements. Subsequently, the element force vector $\left(\mathrm{P}_{\text {adpt }}\right)$ for the adapter element is updated and returned to the slave assembly.

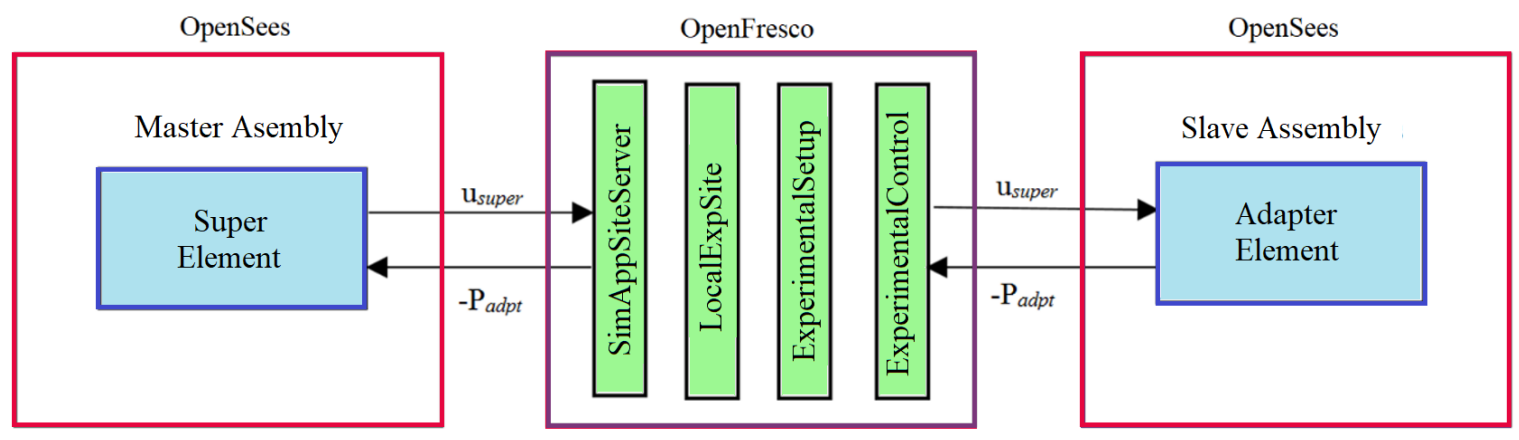

Fig. 1 Sequence of operations and data exchange

Step 5. After the solution convergence from the slave program, the negative resultant force vector $\left(-\mathrm{P}_{a d p t}\right)$ is sent to the 'ExperimentalControl' object through the TCP/IP socket. Again, the storage and transformation of the force vector are carried out by the 'LocalExpSite' and 'ExperimentalSetup' objects (see Fig. 1).

Step 6. The 'SimAppSiteServer' then sends the force vector to the super element in the master program through the TCP/IP socket.

Step 7. The master program then determines the new trial displacements and Step 1 to Step 7 are repeated until the analysis is complete.

The analysis is performed in two stages, similar to the Mokrsko fire test. In the first stage, a static load of $5.6 \mathrm{kN} / \mathrm{m}^{2}$ with a load ratio of 0.26 is applied uniformly on the beam. In the second stage, the time-temperature curves obtained from the test are applied at various locations along the beam, in accordance with the available information (see Fig. 2) (Wald et al., 2011). 


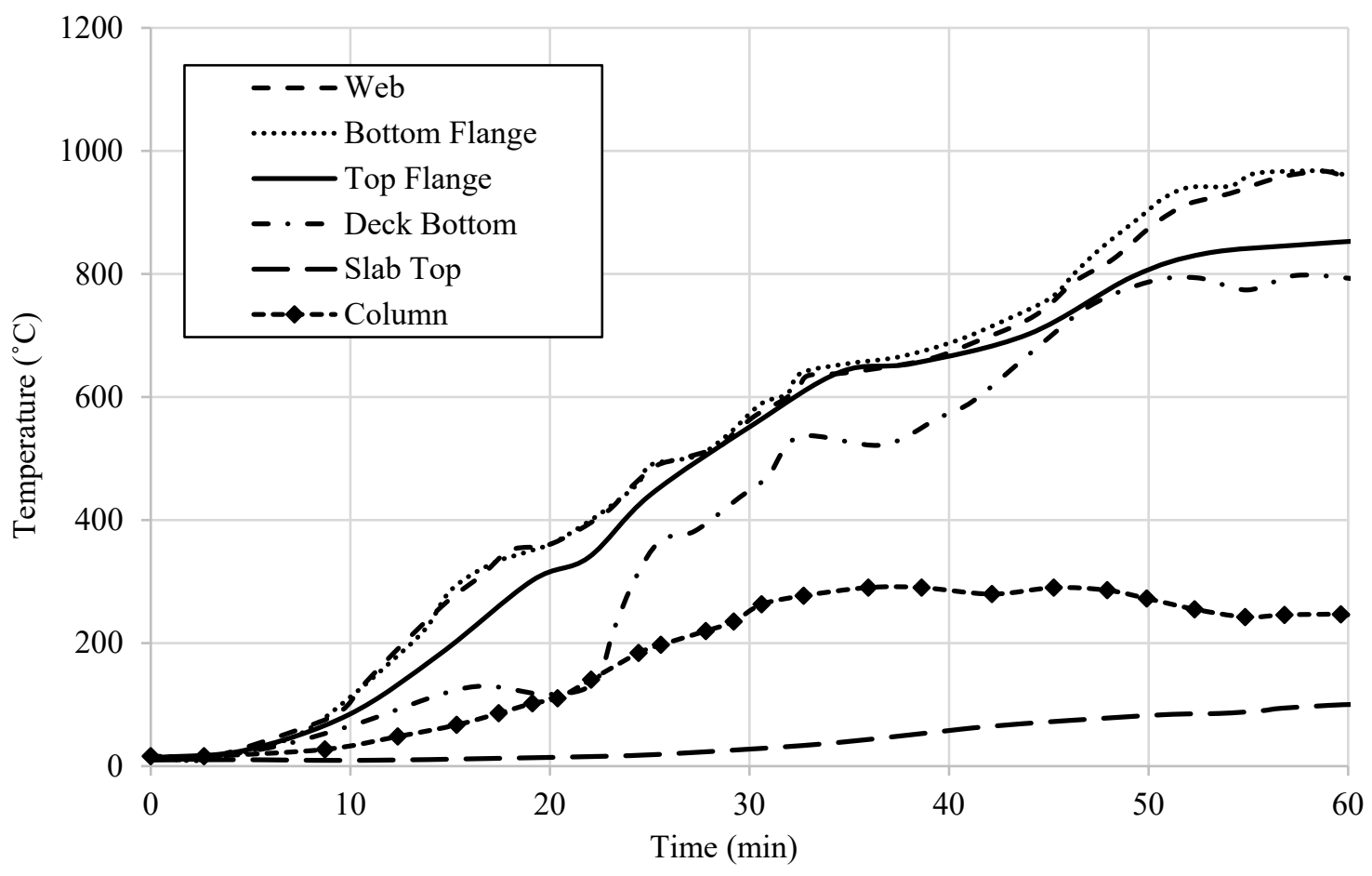

Fig. 2 Temperature profile at the various location (Wald et al., 2011)

\subsection{Validation}

Fig. 3 presents the mid-span vertical deflections of the restrained composite cellular beam (AS2) with increasing time, as predicted by the numerical simulation together with the experimental results. It is clear that a reasonable agreement is achieved and the virtual hybrid simulation framework is capable of providing a good prediction of the true response.

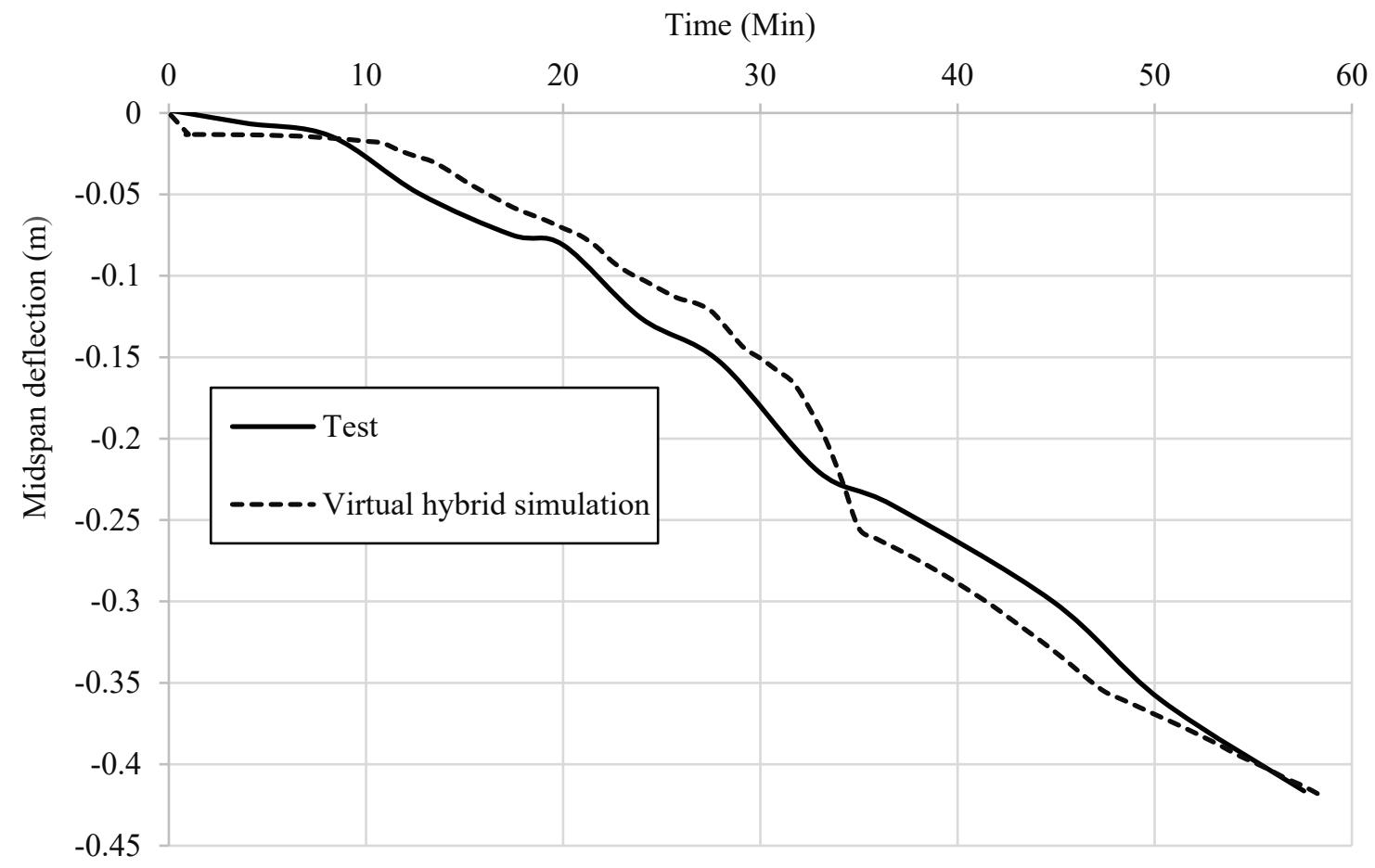

Fig. 3 Vertical deflection comparison at mid-span 


\section{Parametric study and discussion}

Following the validation of the framework, the virtual hybrid simulation model is employed to study the effect various important parameters such as opening location, support conditions and fire scenario on the behaviour of composite perforated beams. In terms of the opening arrangements, four cases are included in the investigation, as follows:

- Case 1: Openings in the centre (bending zone) of a composite perforated beam with axial and rotational support through virtual hybrid simulation;

- Case 2: Openings $500 \mathrm{~mm}$ from the end (shear zone) of a composite perforated beam with axial and rotational support through virtual hybrid simulation;

- Case 3: Openings in the centre (bending zone) of a simply supported composite perforated beam; and

- Case 4: Openings $500 \mathrm{~mm}$ from the end (shear zone) of a simply supported composite perforated beam.

Fig. 4 presents a graphical representation of the beam, indicating the size and positions of the openings. All of the cases are analysed in two phases whereby the mechanical load is first applied and this is then followed by the application of thermal loading. The beam in each case is exposed to the same thermal loading as experienced by AS2 test beam, as previously described. In terms of investigating the effect of the interaction of the AS2 beam with the surrounding structure, both restrained beams, using virtual hybrid simulation (Case 1 and 2), and simply supported beam arrangements (Case 3 and 4) are considered. For Case 1 and 2, the framework outlined in Section 2 of this paper is utilised. On the other hand, in the simply supported simulations, an isolated simply supported beam is modelled without including the rest of the structure.

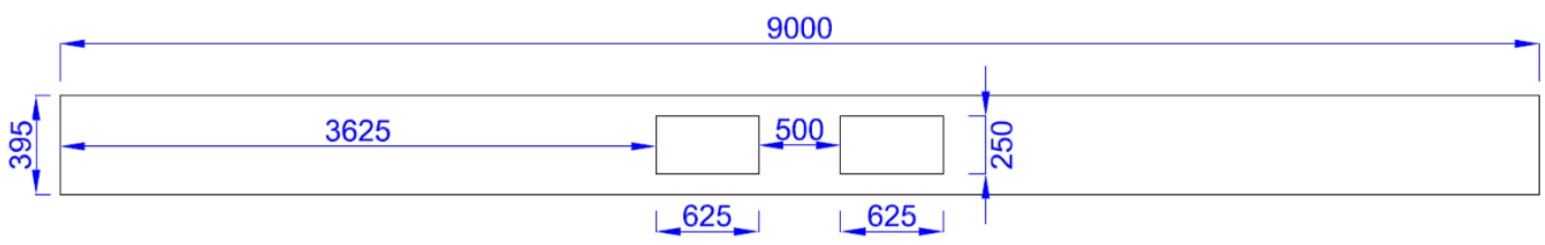

(a)

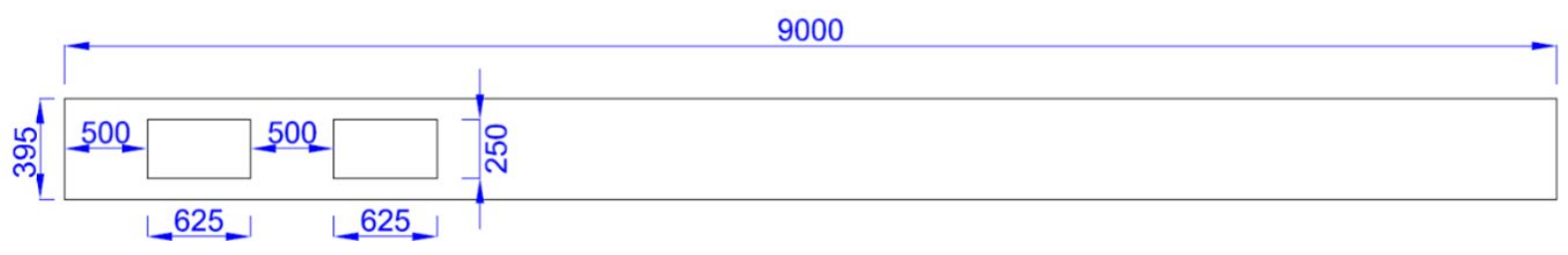

(b)

Fig. 4 Opening layout for (a) Case 1 and 3 and (b) Case 2 and 4 (all dimensions are in mm) 
Another important parameter which is investigated is the effect of different fire scenarios. Three fire scenarios are considered for this study, including a standard fire, slow parametric fire and fast parametric fire. The time-temperature curves for the parametric fires are generated in accordance with the Eurocode guidelines (EN 1991-1-2, 2005).

\subsection{Opening layout}

In order to analyse the effect of the opening locations on the overall performance, Fig. 5 presents the development of mid-span vertical defections as a function of time for all opening arrangements, while the axial forces and the horizontal axial displacements in the member are given in Figs. 6 and 7, respectively. This sub-section focuses only on the effect of opening layout by analysing Case 1 and Case 2, whereas the following sub-section deals with boundary condition effects, and assesses Case 3 and 4. Fig. 5 illustrates that for Case 1, the beam deflects in an upward direction initially. This behaviour is explained by inspecting the thermal profiles across the depth of the beam (See Fig. 1), which show that the temperature in the bottom flange increases at a rapid rate compared with the temperature of the web, top flange and slab.

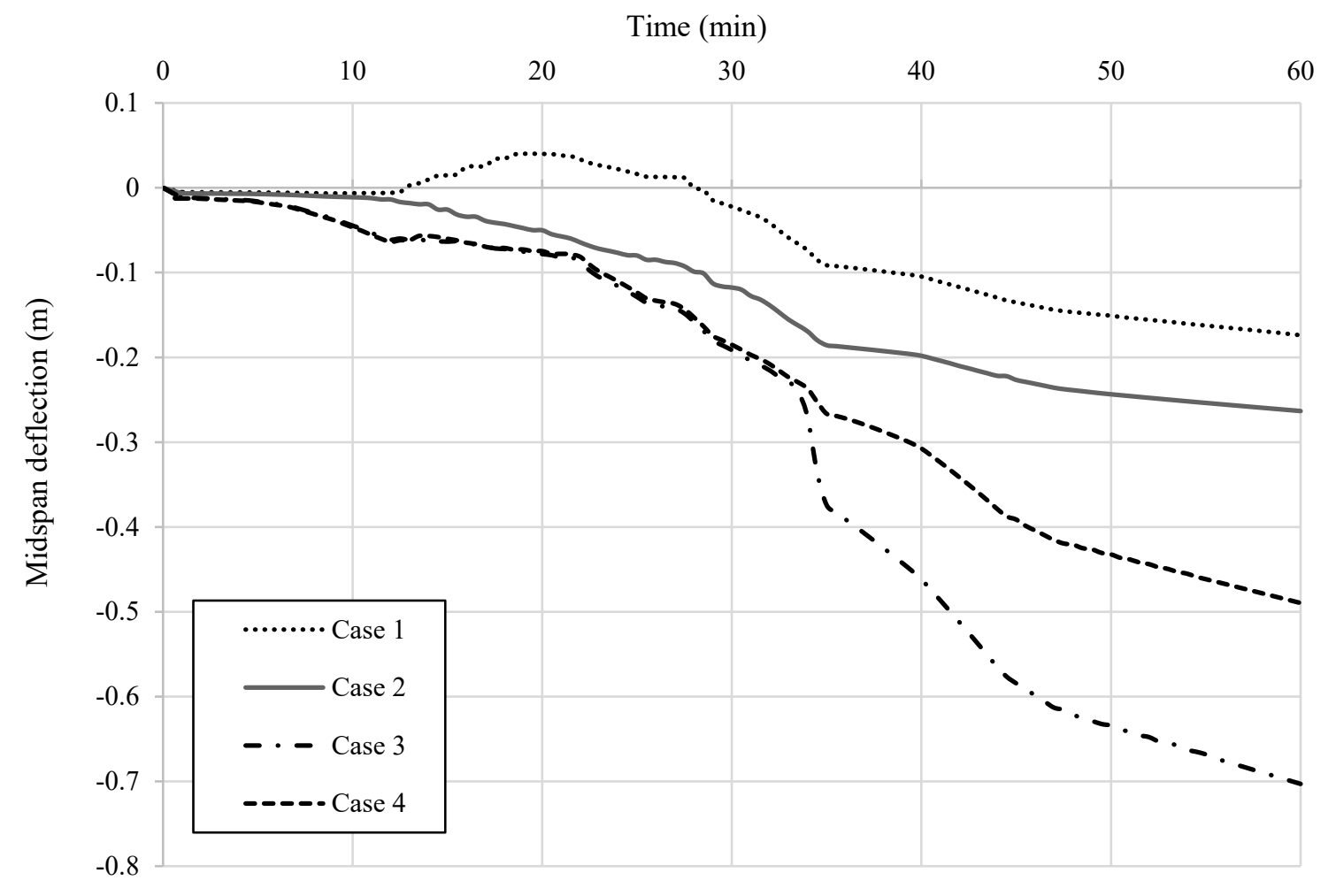

Fig. 5 Time-deflection behaviour of various cases

As a result, for the initial 20 minutes, the compressive force that develops in the bottom teesection of the perforated beam due to the restrained thermal expansion exceeds the combined 
compressive force, which develops in the top tee and slab, as shown in Fig. 6(a). This unbalanced compressive force generates a hogging moment in the beam causing the beam to deflect in an upward direction.

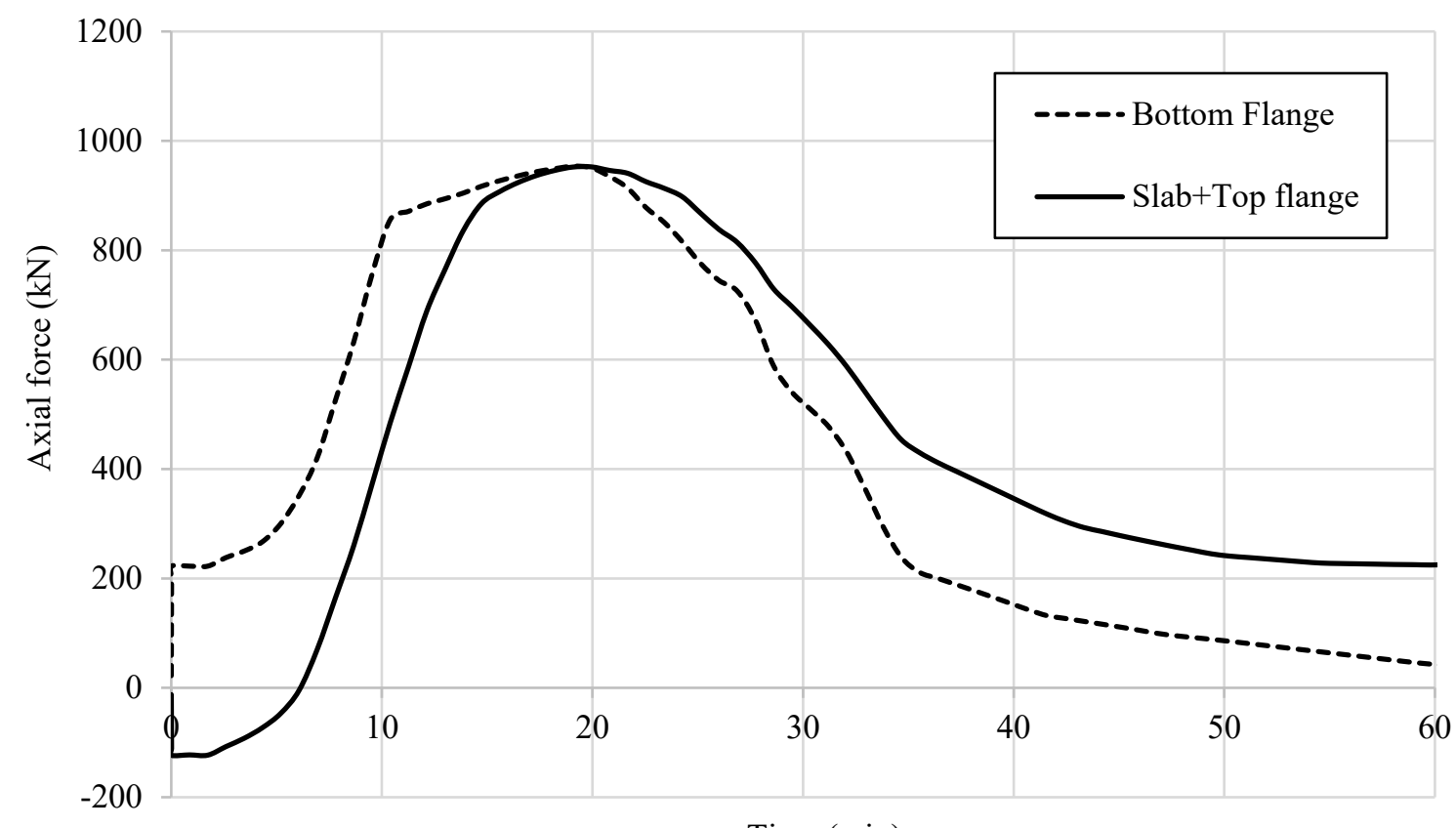

Time (min)

(a)

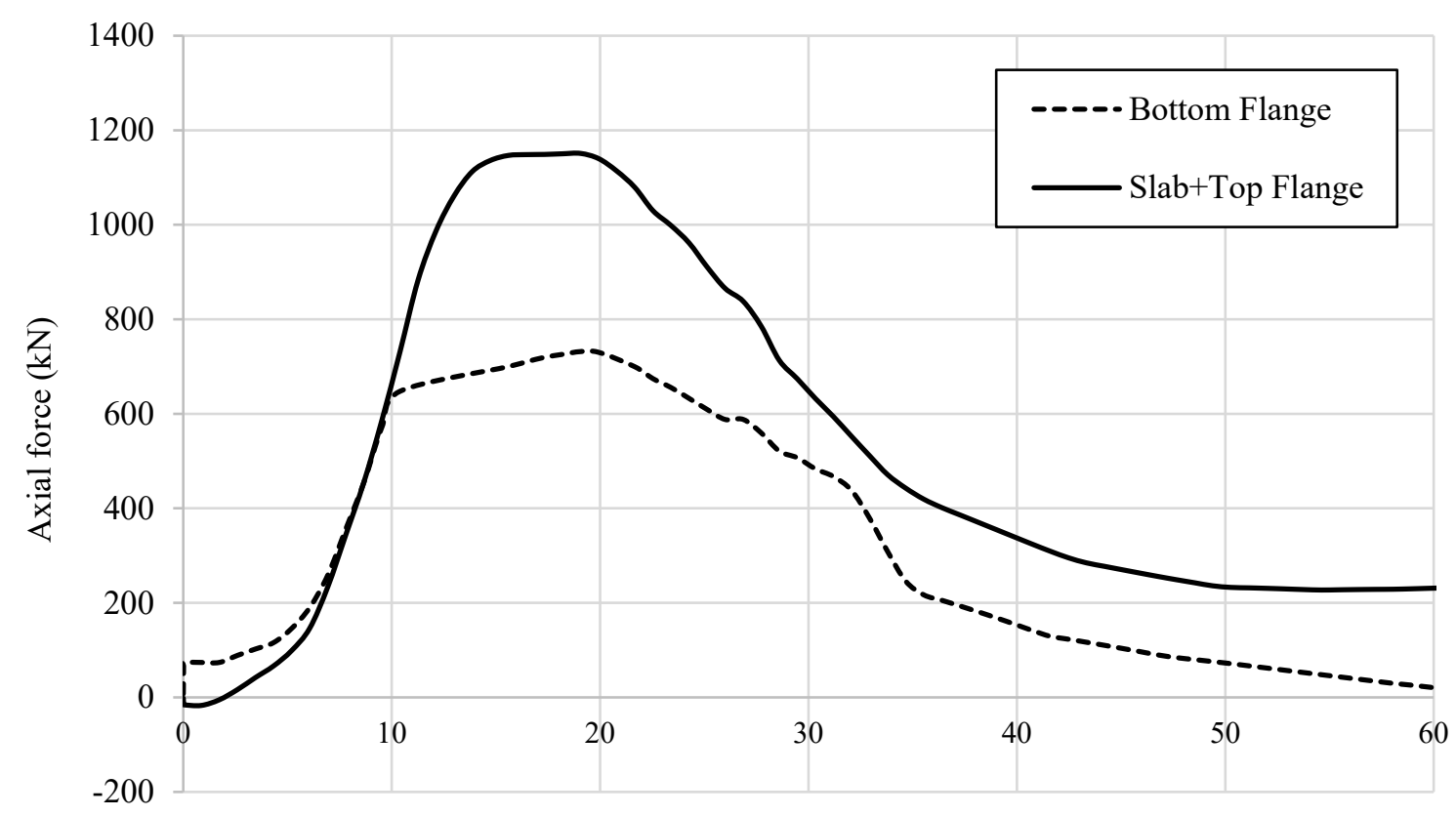

Time (min)

(b)

Fig. 6 Development of axial forces in the member with (a) openings in the bending zone, Case 1, and (b) openings in the shear zone, Case 2 
However, at the onset of yielding of the bottom tee under the compressive force, it starts to deflect in the downward direction. The level of ultimate downward deflection is reduced owing to the initial upward movement. On the other hand, for Case 2 the opening is present near the end of the beam in the shear zone and therefore partial axial and rotational restraint develops in this region. The lower levels of compressive and tensile forces for Case 2 compared with Case 1 during the initial phase of the analysis can be seen in Fig. 6(a) and (b). As a result of this restraint, any hogging moments which develop are not significant enough to cause upward deflections in the member, as occurred for Case 1. Therefore, as well as the presence of a solid web at the midsection of the beam, the Case 2 beam deflects downwards for the duration of the fire. This behaviour is further shown with reference to Fig. 6(a) and (b) for Case 1 and 2, respectively. In addition, Fig. 6(b) shows that for most of the duration of the fire, the combined compressive force in the slab and the top flange is greater than the compressive force that develops in the bottom flange of the composite beam.

Similarly, analysis of the horizontal end displacements for both Case 1 and Case 2 as presented in Fig. 7(a), shows that Case 1 (where high support restraints are experienced) experiences greater levels of end displacements compared to Case 2, where the openings are at the ends of the beam. There is a fundamental difference in the behaviour between restrained composite perforated beams with openings in the bending zone (Case 1) and shear zone (Case 2).

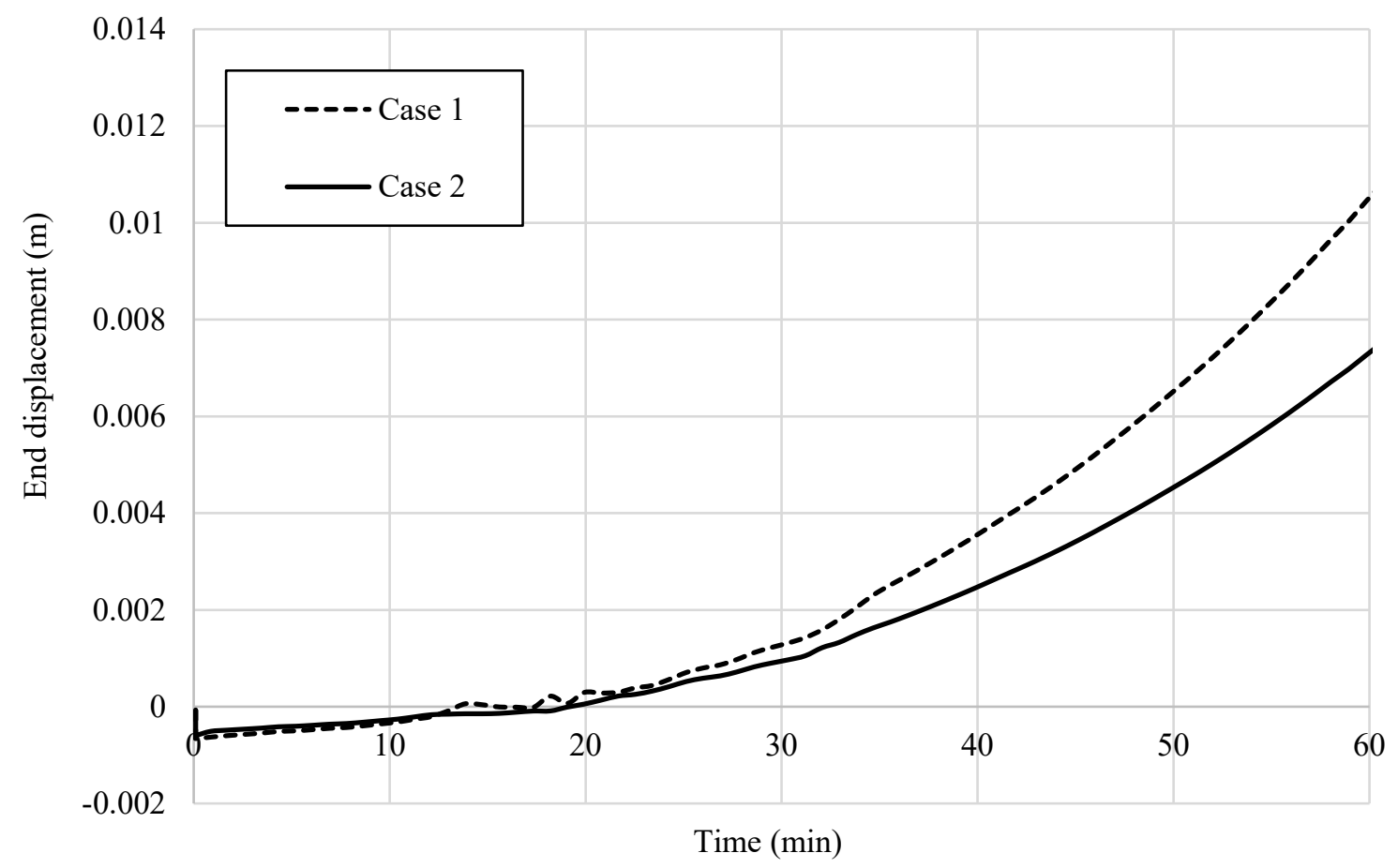

(a) 


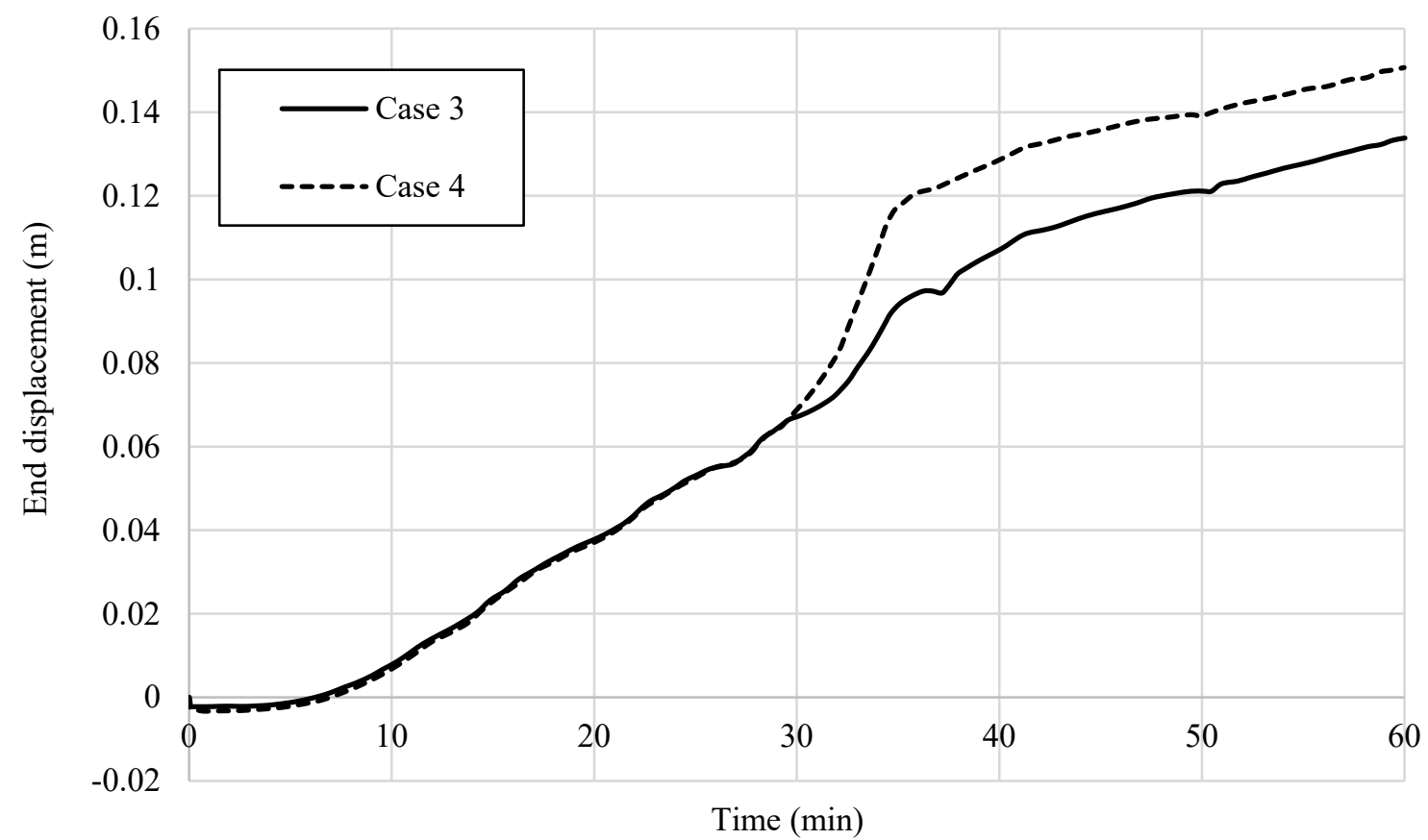

(b)

Fig. 7 Variation of the end displacement in the member for (a) restrained beams using virtual hybrid simulation and (b) simply supported beams.

The Case 2 beams are required to resist larger hogging moments and shear forces compared with the Case 1 beam, in addition to axial forces and Vierendeel bending. As a result, the primary failure mode for these beams is Vierendeel mechanism. In this mechanism, transverse shear is transferred across the opening which leads to the formation of plastic hinges at the corners of the opening. On the other hand, similar beams in the Case 1 arrangement experience lower levels of hogging moments and shear force and no Vierendeel bending is observed. In this instance, due to the presence of high axial compressive force, a yielding of the bottom teesection is observed as the main failure mode. Based on the data and analysis presented in this section, it is concluded that for restrained composite beams, an improved fire performance is obtained for members that have openings in the bending zone rather than in the shear zone.

\subsection{Boundary conditions}

In this sub-section, the fire behaviour of restrained composite perforated beams as in Case 1 and 2 are compared with similar beams with simply supported end conditions (Case 3 and Case 4) as presented in Fig. 5. With reference to Fig. 5, it is clear that the behaviour is very different, depending on the support conditions. In the analysis of the restrained beams in the previous sub-section, it is shown that members with openings in the shear zone (Case 2) are more critical compared with Case 1, with higher mid-span deflections and inferior fire performance. 
However, for the simply supported members, Case 3 (with openings in the bending zone) exhibits greater mid-span deflections and poorer fire resistance compared with Case 4 (openings in the shear zone). The absence of axial and rotational restraint does not allow the development of hogging moments in the simply supported beams. Accordingly, there is no initial upward movement in the Case 3 beam, as was observed in Case 1. Due to the openings at the mid-span, the section becomes weak in this region as the temperature rises and the moment resisting capacity decreases which results in greater mid-span deflections. This is further shown with reference to the vertical and end displacements presented in Figs. 5 and 7(b), respectively, where Case 3 experiences greater vertical deflection but lesser horizontal displacements, compared with Case 4. Therefore, it is concluded that for simply supported perforated composite beams, members with openings in the shear zone perform better in fire conditions, compared with beams that have openings in the middle of the members.

\subsection{Fire scenario}

In this section, the virtual hybrid simulation model is employed to assess the behaviour of restrained composite perforated beams exposed to three different types of fire scenario as shown in Fig. 8, namely a standard fire, a fast parametric fire and a slow parametric fire (EN 1991-1-2, 2005). A number of different fire models are available in the literature but these are selected as they are the most commonly found in research literature and also in design methods. Alam et al. (2018a; b) used similar fire models to analyse the effect of different fire scenarios on the behaviour of slim floor beams. The parametric fires (both fast and slow) have been generated in accordance with the Eurocodes (EN 1991-1-2, 2005) by adopting the following values. It is assumed that the compartment represents a typical office building and the design value of fire load density $\left(\mathrm{q}_{\mathrm{t}, \mathrm{d}}\right)$ is $200 \mathrm{MJ} / \mathrm{m}^{2}$ in both parametric fire scenarios. An opening factor of $0.02 \mathrm{~m}^{1 / 2}$ is used to achieve the slow fire time-temperature curve, which is the minimum value in accordance with the Eurocodes (EN 1991-1-2, 2005), whereas for the fast fire exposure a higher opening factor of $0.1 \mathrm{~m}^{1 / 2}$ is used. The density, specific heat and thermal conductivity of the compartment boundaries are represented by the ' $b$ ' factor and the value used for both the fire scenarios is $1250 \mathrm{~J} / \mathrm{M}^{2} \mathrm{~s}^{1 / 2} \mathrm{~K}$. The time-temperature curves for all three fire scenarios, i.e. standard fire, slow parametric fire and a fast parametric fire are shown in Fig. 8. As before, the analysis is conducted in two phases. In the first phase, a heat transfer analysis is conducted to determine the temperature history at various locations in the beam and this temperature information is then input into to the model and a thermomechanical analysis is completed. 


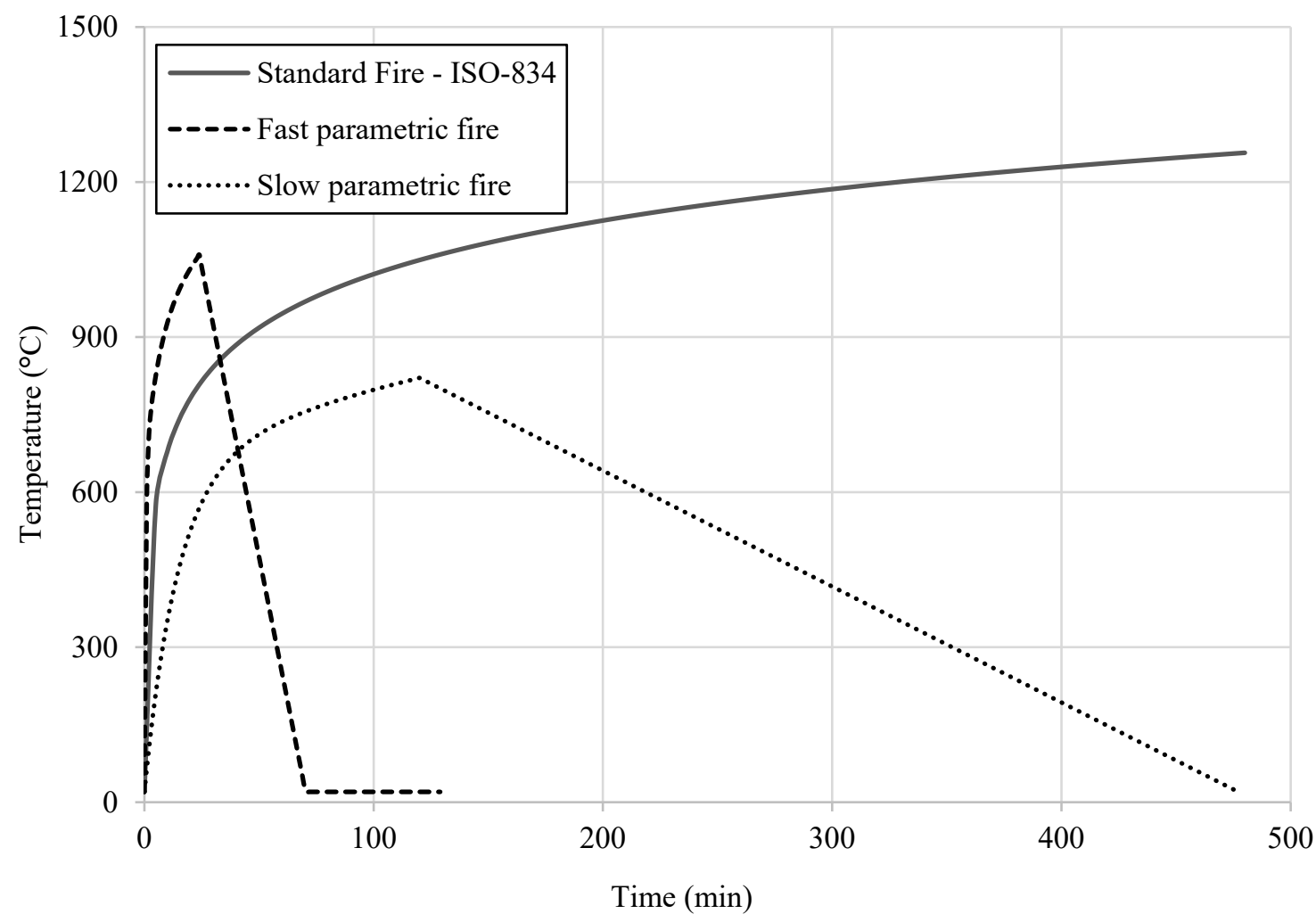

Fig. 8 Different fire curves used in the analysis

\subsubsection{Assessment of the heat transfer analysis}

A thermal heat transfer analysis has been conducted for all three fire scenarios, resulting in the distribution of elevated temperatures and thermal gradients across the depth of the section. The thermal gradient in a portion of whole of the section is determined as the maximum difference in temperature across that element. The results are presented in Figs. 9 to 11 and it is clear that in a standard fire, the average temperatures and thermal gradients continue to rise for the whole duration of the fire because of the absence of a cooling branch. On the other hand, for the parametric fires, the average temperature as well as the thermal gradient decrease after reaching a maximum value due to the rapid cooling of the steel section compared with the concrete slab. Due to relatively high thermal conductivity, low specific heat and thin elements, the steel section develops very high temperatures and relatively little thermal gradient during any of the three fire scenarios. On the other hand, a more significant thermal gradient develops across the concrete slab and the whole composite beam.

As expected, the greatest thermal gradient is found for the beam subjected to a fast parametric fire. In the first 30 minutes of the fire, the thermal gradient is very high with a maximum temperature difference of $972^{\circ} \mathrm{C}$. This thermal gradient decreases suddenly to a very small 
value of $206^{\circ} \mathrm{C}$ after 80 minutes of fire exposure due to the sharp cooling branch of the fast fire time-temperature curve.

On the other hand, for the standard fire, both the thermal gradient and the average temperature in the section increases for the whole duration of the fire because of the absence of a cooling branch. The maximum temperature difference is this case is $847^{\circ} \mathrm{C}$ after 120 minutes of the standard fire exposure, as illustrated in Fig. 9. For comparison, it is worth noting that at 30 minutes, the maximum tempearture difference is $743^{\circ} \mathrm{C}$, whereas it was $972^{\circ} \mathrm{C}$ for the fast paramtric fire, and in general, the rate of development of a thermal gradient across the section is slower compared with the fast fire. Similar observations for slim floor beams exposed to different fire scenarios were reported by Alam et al. (2018).

When the structure is exposed to a slow parametric fire, the development of thermal gradient in the section is the least significant of the three scenarios examined. The maximum temperature difference obtained is $532^{\circ} \mathrm{C}$ after $120 \mathrm{~min}$ of heating as shown in Fig. 11. After 30 minutes, the temperature difference is $452^{\circ} \mathrm{C}$. In the cooling phase, greater average temperatures and thermal gradients are observed in the slow parametric fire compared with the fast fire, owing to a slower rate of cooling.

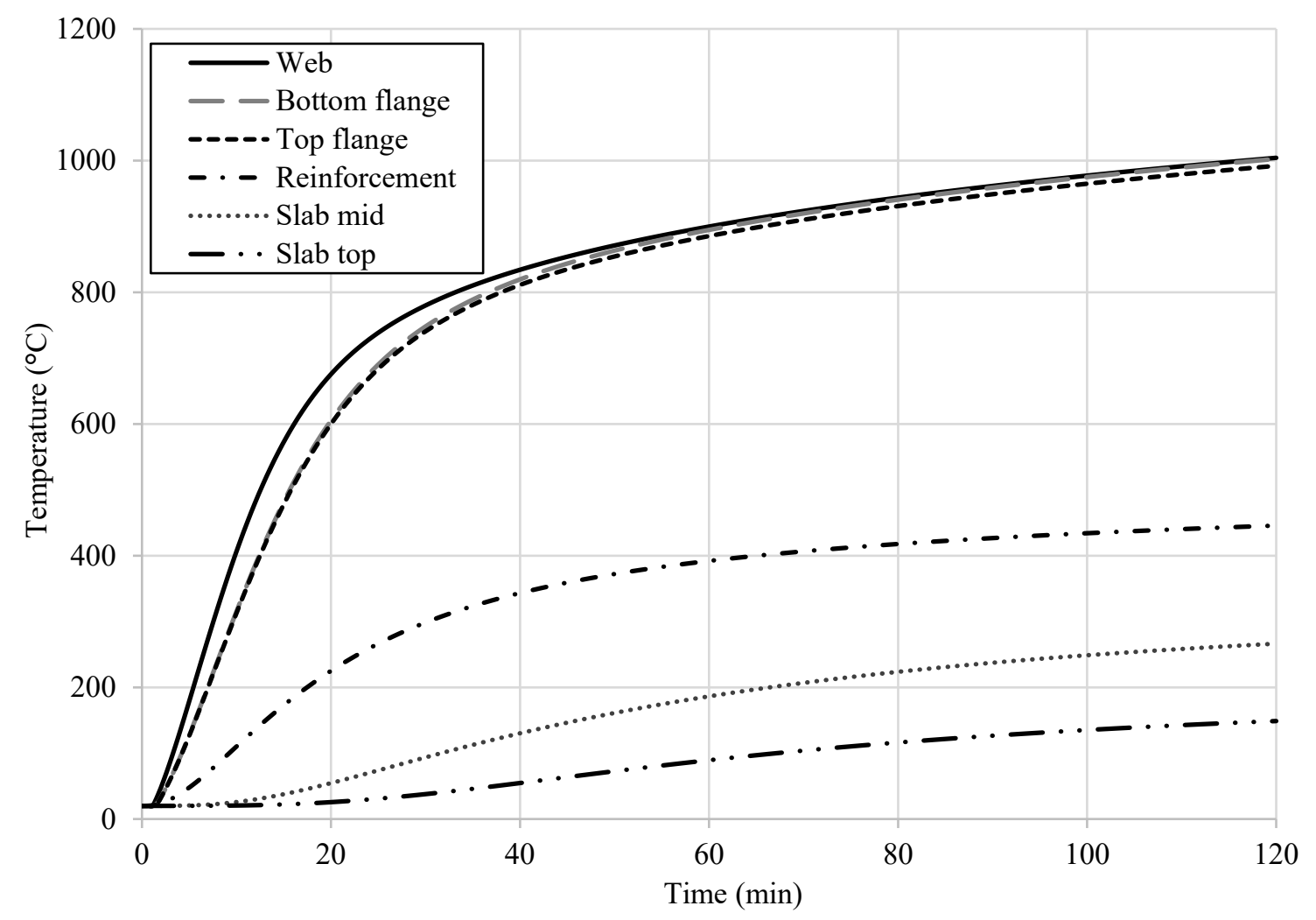

Fig. 9 Temperatures at various location of the beam exposed to the standard fire 


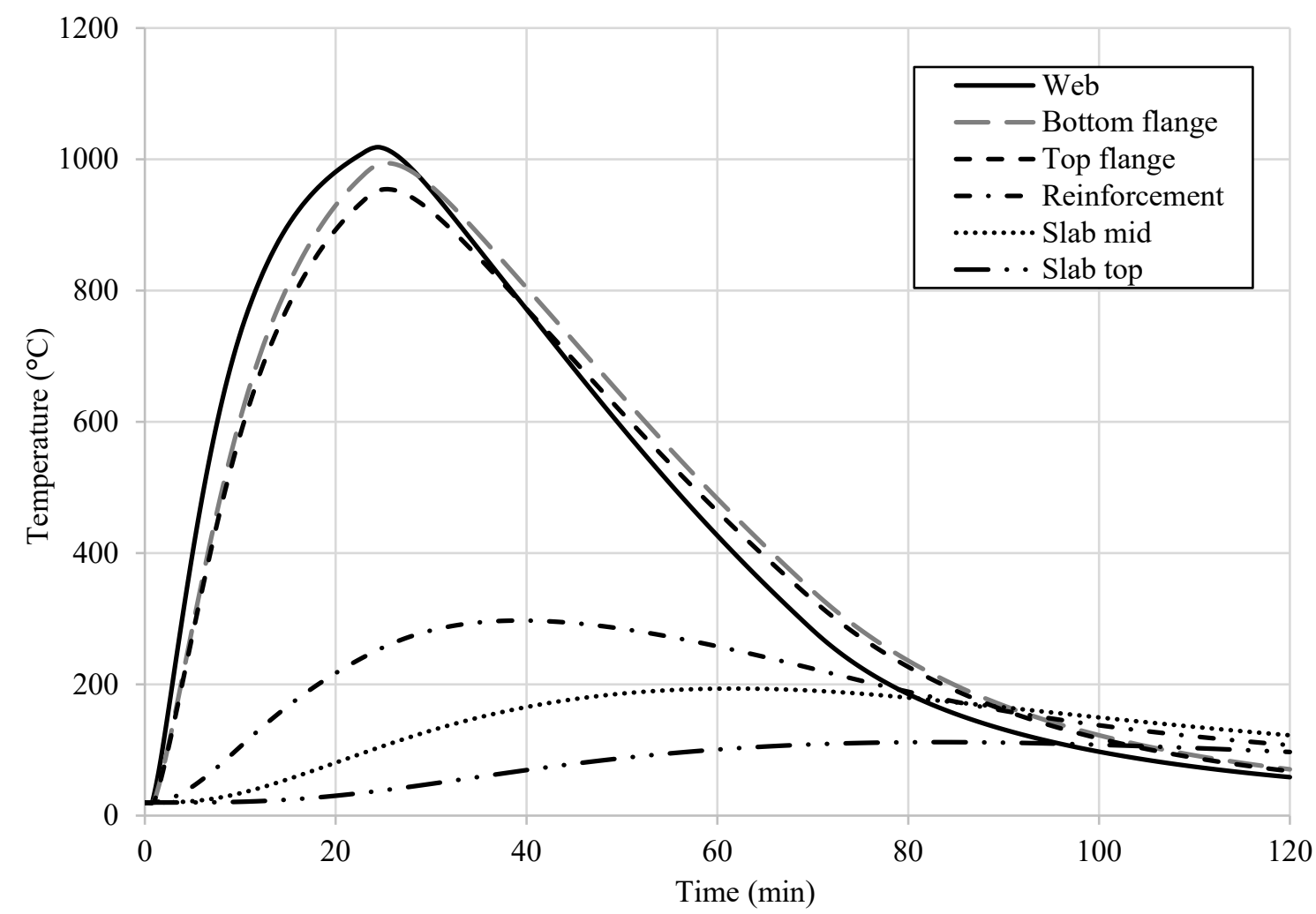

Fig. 10 Temperatures at various location of the beam exposed to fast parametric fire

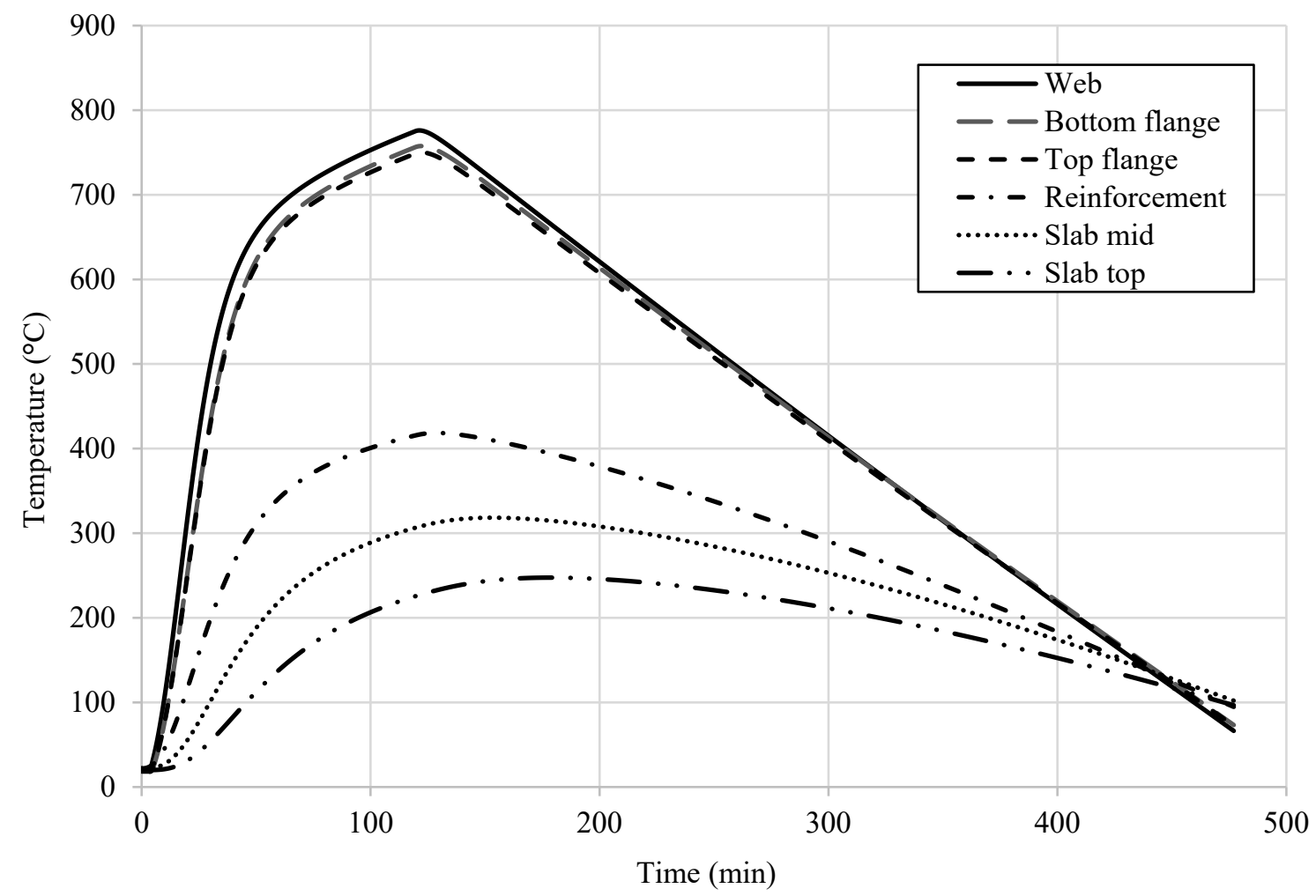

Fig. 11 Temperatures at various location of the beam exposed to slow parametric fire 


\subsubsection{The thermomechanical analysis}

The effect of different fire scenarios on the structural response of the restrained composite perforated beams is analysed in terms of the mid-span deflections predicted for the standard and parametric fire exposures. The failure criteria employed herein are adopted based on those given in BS 476-20 (1987), which employs a maximum deflection limit of L/20 and maximum deflection rate of $\mathrm{L}^{2} / 9000 \mathrm{~d}$ (once the deflection exceeds $\mathrm{L} / 30$ ), where $\mathrm{L}$ is the length of the beam and $\mathrm{d}$ is the overall depth of the section. Fig. 12 presents the time versus mid-span deflection behaviour for perforated beams with openings in the bending zone which are exposed to different fire scenarios. It is clear that the fast parametric fire leads to the greatest levels of deflection, followed by the standard fire whilst the slow parametric fire generally results in the lowest defections.

As stated before, Case 1 beams experience an initial upward deflection due to the development of thermal gradient in the section. Due to the relatively high average temperature and thermal gradients, the mid-span deflections for the structure exposed to a fast parametric fire is greater than for the other fire types for most of the fire duration. The maximum deflection obtained during the heating branch of fast fire exposure is $262 \mathrm{~mm}$. On the other hand, for the slow fire exposure, the mid-span deflections are significantly lower than for the fast parametric or standard fire which is attributed to the lower thermal gradient and lower average temperature. The deflection limit of $450 \mathrm{~mm}$, corresponding to L/20, is reached after 64 and 80 minutes for the fast parametric and standard fires, respectively. The maximum deflection obtained for the slow parametric fire is $100 \mathrm{~mm}$ and it does not reach limiting deflection as shown in Fig. 12. A runaway deflection is observed only in the case of a standard fire exposure, and this occurs after 95 minutes. Due to the continual increase of the average temperature of the section in the standard fire, the strength of concrete and steel are reduced significantly which results in a runaway deflection.

As shown in Fig. 13, similar behaviour is observed for beams with openings in the shear zone although the beams reach to the limiting deflection and runaway failure at an earlier point. The limiting deflections are reached after 60 and 65 minutes for the fast parametric and standard fire exposures, respectively. For both fire exposures, the Case 2 beams reaches the limiting deflection prior to the Case 1 beams. Again, the beam exposed to slow parametric fire does not reach the limiting deflection and the maximum deflection is $205 \mathrm{~mm}$ when the openings are in the shear zone compared with $100 \mathrm{~mm}$ for the members with openings in the bending zone. It 
is noteworthy that only the beam subjected to a standard fire experiences runaway failure which occurs after 73 minutes.

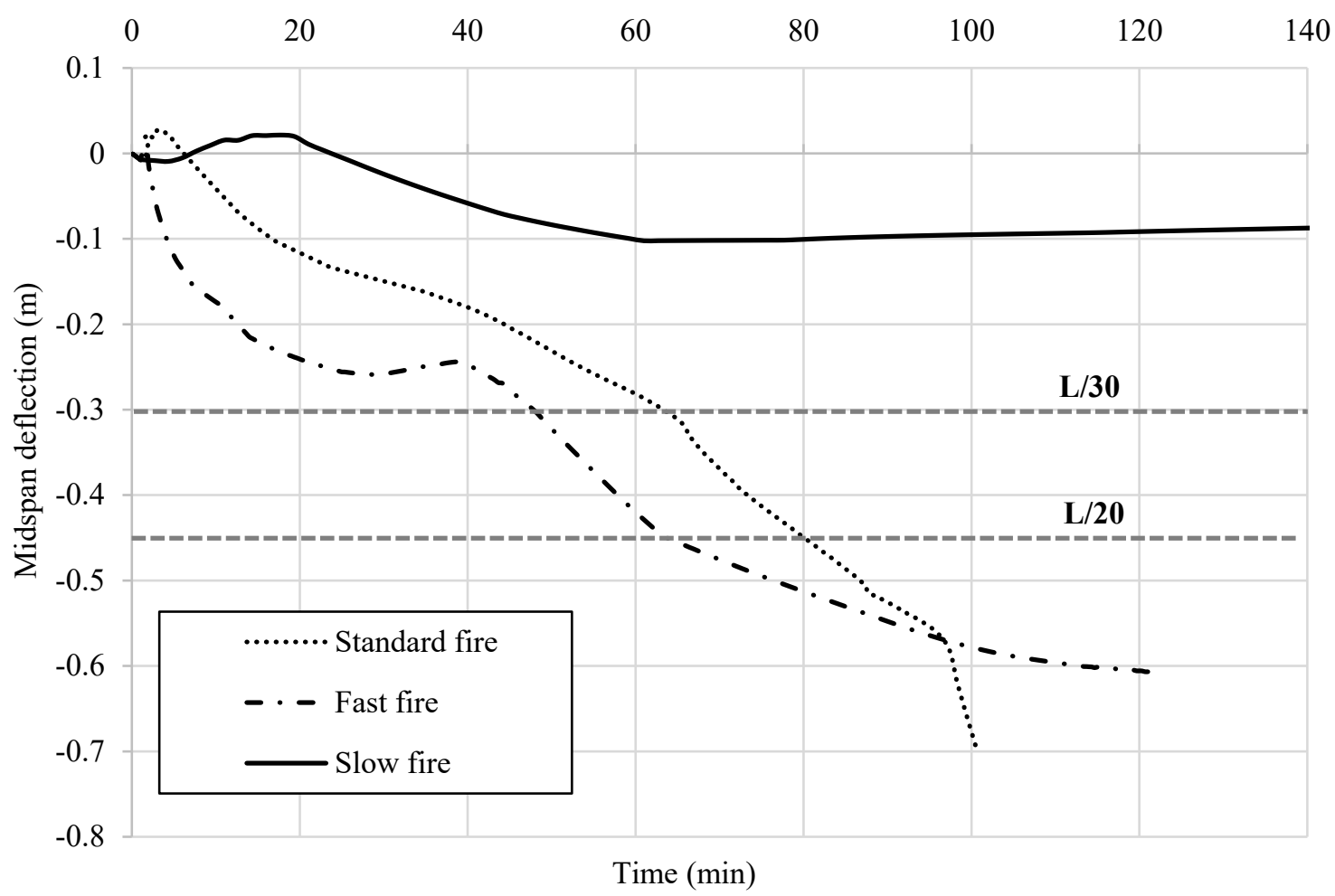

Fig. 12 Mid-span deflection of the beam with the openings in the bending zone for different fire exposure

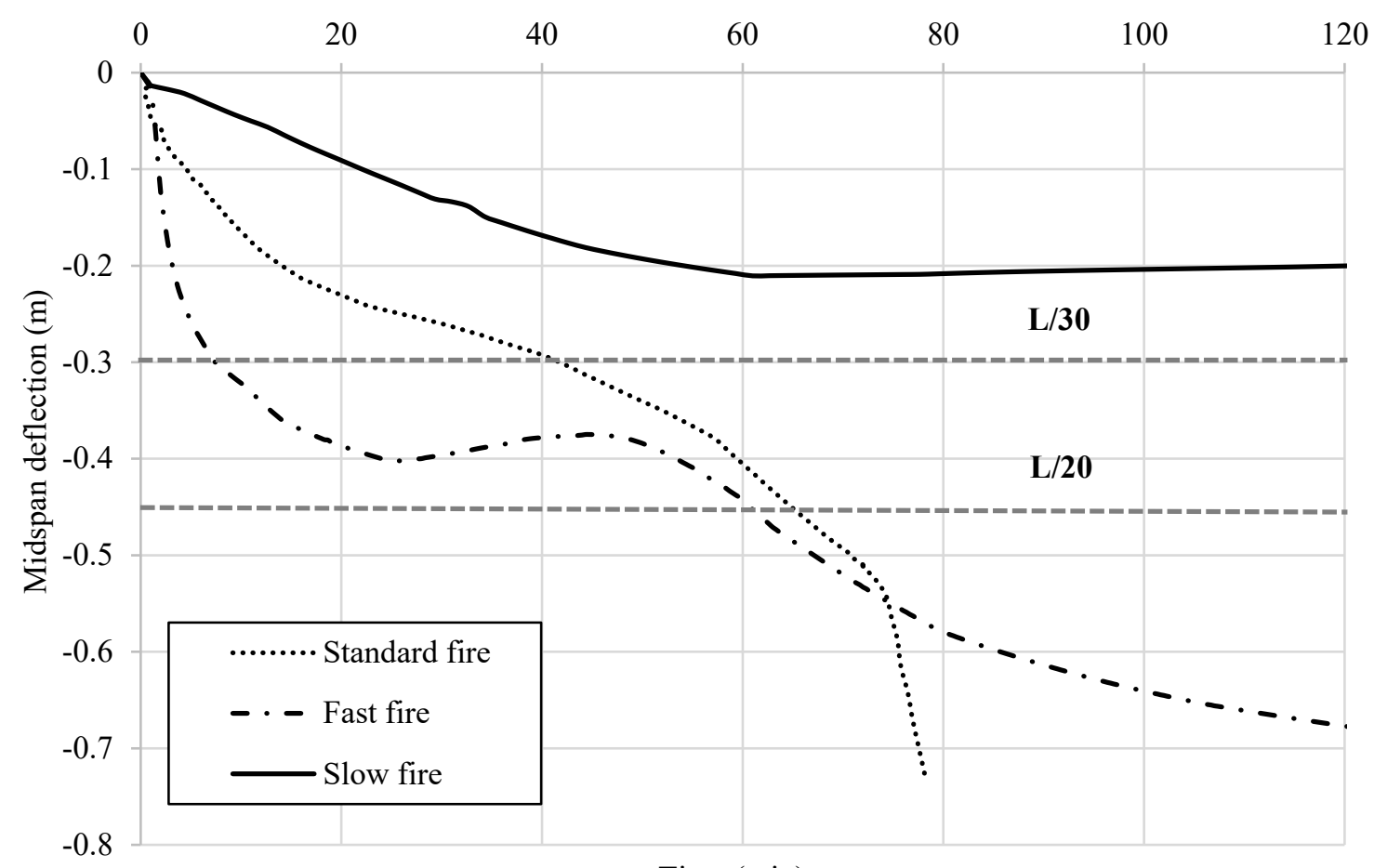

Time (min)

Fig. 13 Mid-span deflection of beam with openings in the shear zone for different fire exposure 
In summary, it is clear that during the initial stages of fire, the behaviour of composite perforated beams is governed by the rate of heating and the thermal gradients that develop in the section. Greater thermal gradients result in higher mid-span deflections and earlier attainment of the prescribed deflection limits. On the other hand, the ultimate failure of composite perforated beams is mainly governed by the average temperature of the section which reduces the overall strength of the section and causes collapse in the form of runaway deflection. This implies that the structural response of composite perforated beams is a function of the average temperatures and thermal gradient across the composite beam section.

\section{Conclusions}

This paper presents a study into the behaviour of restrained perforated beams exposed to fire using a virtual hybrid simulation technique. Simply supported boundary conditions are also assessed, using a straight forward, single-analysis, finite element model. For the restrained beams simulated using the virtual hybrid simulation technique, compressive forces develop initially in the whole section and, as the material properties gradually degrade, the distribution of forces returns to its original state, which is compression at the top and tension in the lower portion of the beam, at the mid-span. The combined effect of bending moments, shear forces, axial forces and Vierendeel bending results in the beams with openings in the shear zone (Case 2) perform in a more critical manner for the restrained beams with a Vierendeel mechanism being the primary mode of failure. On the other hand, for beams simulated with simply supported boundary conditions, the nature of the force distribution in the cross-section remains the same throughout the fire, which is compression in the top portion and tension in the lower section. For the simply supported beams, the beams with openings in the bending zone (Case 3) experience higher mid-span deflections and have less fire resistance compared with the beams with openings in the shear zone, which is converse to the findings for the restrained beams. Finally, it was shown that during the initial stages of a fire, the thermal gradient developed across the section is greatly influenced by the fire model which is used in the numerical analysis. Of the three different fire scenarios studied herein, the fast parametric fire results in greater mid-span deflections during the heating phase and the beams reaches the limiting deflection earlier than for the standard fire or the slow parametric fire. For both locations of openings, a runaway deflection is observed only in the case of a standard fire exposure due to the strength reduction of concrete and steel at elevated temperature. It is concluded that the structural response of composite perforated beams in fire is a function of thermal gradient across the composite beam section and the average temperatures. 


\section{References}

Abu, A., Block, F., Butterworth, N. and Burgess, I. (2009), "Structural fire engineering assessments of the Fracof and Moksko fire tests: An Engineering prediction", Application of Structural Fire Engineering, Prague, Czech Republic, available at: ISBN 978-80-01-04266-3.

Alam, N., Nadjai, A., Ali, F. and Nadjai, W. (2018), "Structural response of unprotected and protected slim floors in fire", Journal of Constructional Steel Research, Vol. 142, pp. 44-54.

Alam, N., Nadjai, A., Maraveas, C., Tsavdaridis, K.D. and Ali, F. (2018), "Response of Asymmetric Slim Floor Beams in Parametric-Fires", Journal of Physics: Conference Series, $\{\mathrm{IOP}\}$ Publishing, Vol. 1107, p. 32009.

British Steel Plc. (1999), The Behaviour of Multi-Storey Steel Framed Buildings in Fire, Swinden Technology centre, Rotherham.

BS 476-20. (1987), "Fire tests on building materials and structures. Method for determination of the fire resistance of elements of construction (general principles)", British Standard Institution, London, United Kingdom.

Dwaikat, M.M.S. and Kodur, V.K.R. (2011), "A performance based methodology for fire design of restrained steel beams", Journal of Constructional Steel Research, Vol. 67, pp. 510-524.

Ellobody, E. and Young, B. (2015), "Nonlinear analysis of composite castellated beams with profiled steel sheeting exposed to different fire conditions", Journal of Constructional Steel Research, Vol. 113, pp. 247-260.

EN 1991-1-2. (2005), "Eurocode 1: Actions on structures - Part 1-2: General actions - Actions on structures exposed to fire", European Commitee for Standardization, Brussels.

EN 1992-1-2. (2004), "Eurocode 2: Design of concrete structures - Part 1-2: General rules - Structural fire design", European Commitee for Standardization, Brussels, available at: papers2://publication/uuid/1B0960C1-28E7-4B6A-ADFE-19C0455EDFD3.

EN 1993-1-2. (2005), "Eurocode 3: Design of steel structures - Part 1-2: General rules - Structural fire design", European Commitee for Standardization, Brussels.

Jiang, L. and Usmani, A. (2018), "Computational performance of beam-column elements in modelling structural members subjected to localised fire", Engineering Structures, Vol. 156, pp. 490-502.

Khan, M.A., Jiang, L., Cashell, K.A. and Usmani, A. (2018), “Analysis of restrained composite beams exposed to fire using a hybrid simulation approach", Engineering Structures, Elsevier, Vol. 172 No. May, pp. 956-966.

Kolozvari, K., Orakcal, K. and Wallace, J.W. (2018), "New OpenSEES models for simulating nonlinear flexural and coupled shear-flexural behavior of RC walls and columns", Computers and Structures, Vol. 196, pp. 246-262.

Kwon, O.-S., Nakata, N., Park, K., Elnashai, A. and Spencer, B. (2007), User Manual and Examples for UI-SIMCOR v2.6 (Multi-Site Substructure Pseudo-Dynamic Simulation Coordinator) and NEES-SAM v2.0 (Static Analysis Module for NEESgrid).

Lawson, R.M. and Hicks, S.J. (1998), “Design of beams with large web openings”, Steel Construction Institute, Berkshire.

Li, G.Q. and Guo, S.X. (2008), "Experiment on restrained steel beams subjected to heating and cooling", Journal of Constructional Steel Research, Vol. 64, pp. 268-274.

Liu, T.C.H., Fahad, M.K. and Davies, J.M. (2002), "Experimental investigation of behaviour of axially restrained steel beams in fire", Journal of Constructional Steel Research, Vol. 58, pp. 1211-1230. 
Maraveas, C., Fasoulakis, Z. and Tsavdaridis, K.D. (2018), "Fire resistance of axially restrained and partially unprotected Ultra Shallow Floor Beams (USFB ${ }^{\circledR}$ ) and DELTABEAM ${ }^{\circledR}$ composite beams", Applications of Fire Engineering - Proceedings of the International Conference of Applications of Structural Fire Engineering, ASFE 2017, No. September, pp. 81-90.

Maraveas, C., Tsavdaridis, K.D. and Nadjai, A. (2017), "Fire Resistance of Unprotected Ultra Shallow Floor Beams (USFB): A Numerical Investigation”, Fire Technology, Springer US, Vol. 53 No. 2, pp. 609-627.

McKenna, F.T. (1997), "Object-oriented finite element programming: Frameworks for analysis, algorithms and parallel computing", ProQuest Dissertations and Theses.

McKenna, S.T., Jones, N., Peck, G., Dickens, K., Pawelec, W., Oradei, S., Harris, S., et al. (2019), “Fire behaviour of modern façade materials - understanding the Grenfell Tower fire", Journal of Hazardous Materials, Vol. 368, pp. 115-123.

Mostafaei, H. (2012), "A New Testing Capability for Seismic Resistance Assessment of Structures Damaged Due to a Fire", 15th World Conference on Earthquake Engineering, Lisbon Portugal.

Mostafaei, H. (2013), "Hybrid fire testing for assessing performance of structures in fire Methodology", Fire Safety Journal, Elsevier, Vol. 58, pp. 170-179.

Nadjai, A., Bailey, C.G., Vassart, O., Han, S., Zhao, B., Hawes, M., Franssen, J.M., et al. (2011), "Fullscale fire test on a composite floor slab incorporating long span cellular steel beams", Structural Engineer, Vol. 89 No. 21, pp. 18-25.

Nadjai, A., Han, S., Ali, F., Alam, N. and Allam, A. (2017), "Fire resistance of axial restraint composite floor steel cellular beams", Journal of Constructional Steel Research, Vol. 136, pp. 229-237.

Nadjai, A., Petrou, K., Han, S. and Ali, F. (2016), "Performance of unprotected and protected cellular beams in fire conditions", Construction and Building Materials, Elsevier Ltd, Vol. 105, pp. 579588.

Nadjai, A., Vassart, O., Ali, F., Talamona, D., Allam, A. and Hawes, M. (2007), "Performance of cellular composite floor beams at elevated temperatures", Fire Safety Journal, Vol. 42 No. 6-7, pp. 489-497.

Najafi, M. and Wang, Y.C. (2017a), "Axially restrained steel beams with web openings at elevated temperatures, Part 1: Behaviour and numerical simulation results", Journal of Constructional Steel Research, Vol. 128, pp. 745-761.

Najafi, M. and Wang, Y.C. (2017b), "Axially restrained steel beams with web openings at elevated temperatures, Part 2: Development of an analytical method", Journal of Constructional Steel Research, Vol. 128, pp. 687-705.

Pegon, P. and Pinto, A. (2000), "Pseudo-dynamic testing with substructuring at the ELSA Laboratory", Earthquake Engineering \& Structural Dynamics, Vol. 29, pp. 905-925.

Takahashi, Y. and Fenves, G.L. (2006), "Software framework for distributed experimentalcomputational simulation of structural systems", Earthquake Engineering and Structural Dynamics, Vol. 35 No. 3, pp. 267-291.

Usmani, A., Zhang, J., Jiang, J., Jiang, Y., Kotsovinos, P., Zhang, J. and May, I. (2010), "Using OpenSEES for structures in fire", Structures in Fire, Vol. 3 No. 1, pp. 919-926.

Wald, F., Kallerová, P., Chlouba, P. and Sokol, Z. (2011), Fire Test on Administrative Building, Steel and Aluminium Structures, Mokrsko.

Wong, V.B., Brugess, I. and Plank, R. (2009), "Behaviour of composite cellular steel - concrete beams at elevated temperatures", Steel Structures, Vol. 9, pp. 29-37. 
Zhu, M., McKenna, F. and Scott, M.H. (2018), "OpenSEESPy: Python library for the OpenSEES finite element framework”, SoftwareX, Elsevier B.V., Vol. 7, pp. 6-11. 